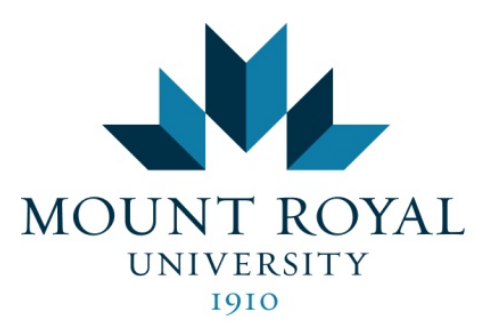

Department of Education and Schooling

Mount Royal Undergraduate Education Review

Volume 1(1)

Spring 2014

\title{
The effects of technology on bullying
}

Katie Lemke, Mount Royal University

\begin{abstract}
I chose this topic for inquiry because I have personal experience with bullying, and I wanted to know what I can do to combat bullying when I am an elementary teacher. Through an online survey and personal interviews, research has been conducted to answer the question whether or not the increased availability of technology to students in, and out, of the classroom has an impact on bullying. My data collection, through the use of an online survey and personal interviews, has led me to believe that the increased availability of technology does have an impact on the number of cases and severity of bullying. The second question that I set out to answer is what can teachers do to recognize and prevent bullying in their classroom. In a twentyfirst century classroom, students need to be educated on how to safely use the Internet. This could include administering a digital citizenship course to students. Teachers must also be aware of the warning signs of bullying in order to recognize when it is happening and stop it in its tracks. The best way that teachers can combat bullying is to educate themselves, and their students about the dangers of bullying. As a future teacher, this information is important for me because it will allow me to do more to combat bullying in my classroom.
\end{abstract}




\section{Introduction}

Bullying at school doesn't just stay at school anymore, It can follow you anywhere you go - Anonymous

When I was in junior high school, I had a run in with a group of bullies that bothered me for an entire year. At this point, I had just moved to Calgary, and I did not have many friends. The girls made me feel insecure and insignificant. This incident occurred before the increased availability of technology in schools. I can only imagine that because of this, the occurrences of bullying in schools today have increased.

I believe that cyber bullying is a huge issue in schools today, one that often goes unnoticed. I am interested to know how much the presence of technology in classrooms can influence the cases of cyber bullying among elementary school aged children. Through my research, I hoped to find information regarding what teachers can do in order to prevent cyber bullying from happening, and also how to recognize when it occurs. As a future teacher, I believe that it is very important for me, and my peers, to know how to recognize when bullying is occurring, and also to know how to prevent it from happening.

The question I have chosen for my research inquiry is: How much of a role does the increase in technology in, and out of, schools play in bullying? How can teachers become more involved in the recognition and prevention of cyber bullying? I used the responses of the participants from my online survey to create a word cloud using the Wordle application that illustrates the main ideas that go along with bullying (Figure 1). 


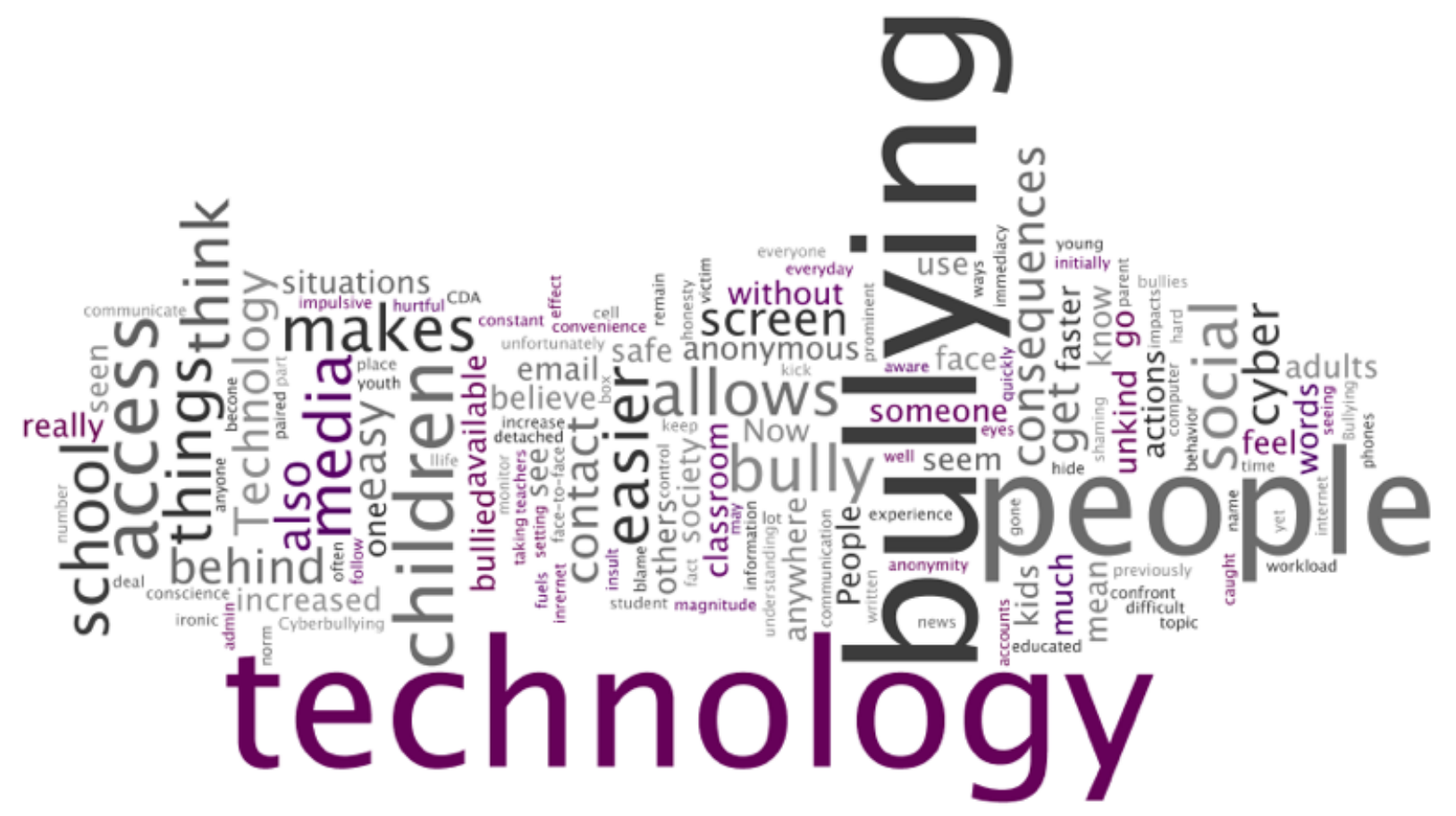

Figure 1. Wordle of bullying

A few terms that I believe are important and should be defined before getting further into this paper are bullying, cyber-bullying, bully, and bystander.

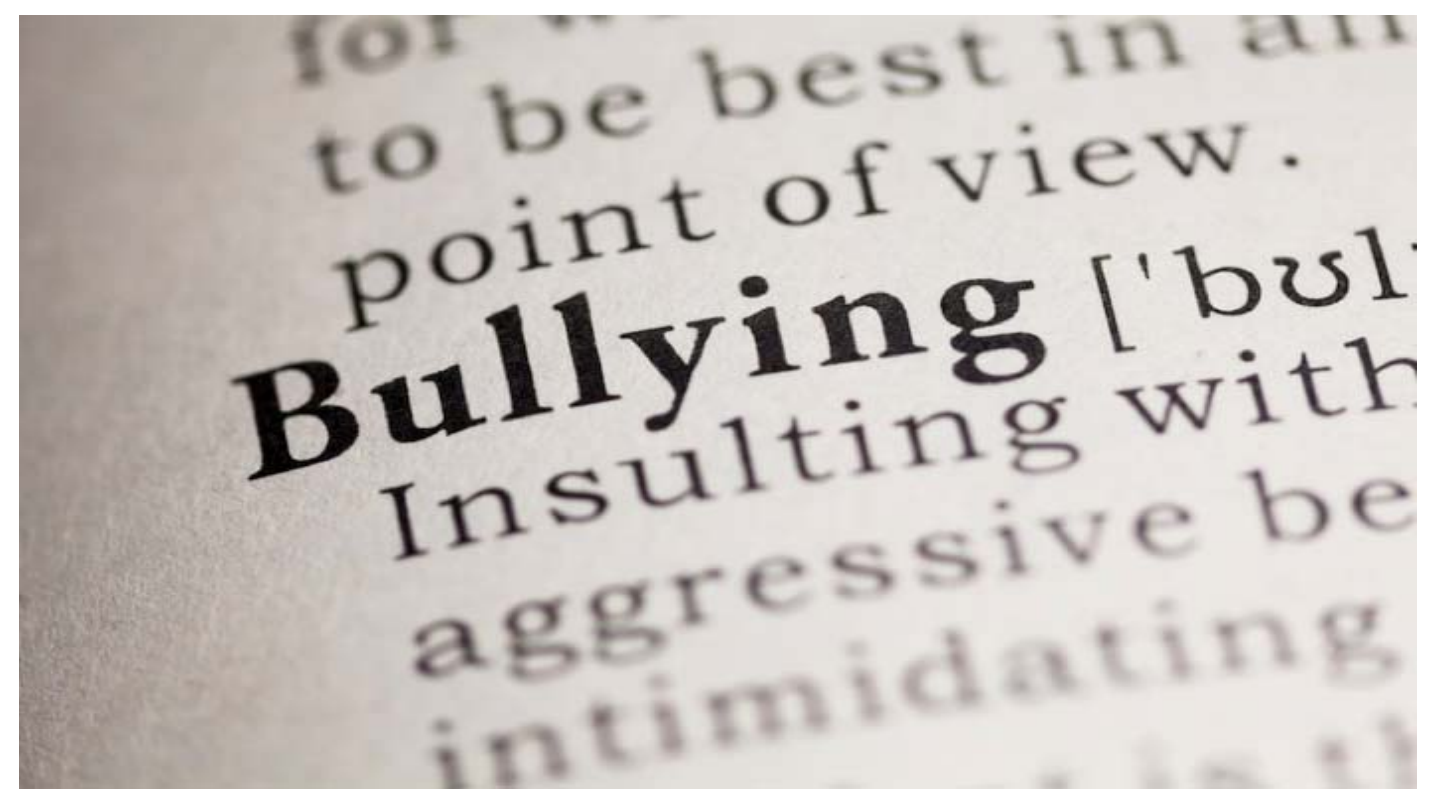

Figure 2. Defining a bully 
Bullying can be described as "affecting by means of force or coercion” (MerriamWebster, n.d.). The verb to bully means "to frighten, hurt, or threaten a smaller or weaker person” (Merriam-Webster, n.d.).

Cyberbullying is "the use of electronic communication to bully a person, typically by sending messages of an intimidating or threatening nature" (Oxford, 2014). Merriam-Webster (n.d.) states that cyberbullying often happens anonymously. A participant in my survey said, "It's a matter of convenience and anonymity. You can say hurtful things to anyone, from anywhere that has Wi-Fi. The fact that sometimes people use accounts from which their identity can't be retrieved makes it so much easier to hurt people. It doesn't seem real if no one can blame you for it”.

A bully can be defined as "a person who uses strength or influence to harm or intimidate those who are weaker” (Oxford, 2014), or “ [someone who] use[s] superior strength or influence to intimidate [someone]" (Oxford, 2014). Merriam Webster (n.d) defines a bully as "one [who is] habitually cruel to others who are weaker”. In a quote from a participant of my survey, they stated: “[technology] gives the bully protection in a way, because they are not having to deal with the consequences of their actions".

A bystander is "[a] person who is present at an event or incident but does not take part" (Oxford, 2014).

\section{Background}

Bullying is a very large issue in today’s society. Cyber-bullying can allow people to bully without being in the same location as others. Therefore, leaving no safe place for victims of bullying. 
Understanding the background of bullying can help us to understand how it will progress in the future. The resources that I have found outline the negative outcomes of bullying in, and out, of the classroom.

In Fredrick's (2009) article, Mean girls (and boys): Cyberbullying and what can be done about it, the mechanisms of cyberbullying are discussed. The article outlines the teacher, and administrations, role in the prevention of cyberbullying. The article discusses specifically the importance of the place of the library staff in the prevention of cyberbullying. Fredrick (2009) provides a succinct definition of cyberbullying: "using the Internet or other mobile devices to send or post harmful or cruel text or images to bully others" (p.44).

In Fredrick’s (2009) article, a possible solution to the problem of cyber-bullying is given. "[Students] need to be given the resources they need to make good choices online and to have the resilience to respond to those who would tear them down” (p. 45). Teachers and administration must work together to "instruct students about cyberbullying and how to combat it” (Fredrick, 2009, p.45). Sometimes students are reluctant to let teachers and other adults know that they are being bullied. Even if students do not feel comfortable telling an adult, if they are educated on how to deal with bullying they will be able to combat it.

Pascarella (2008), looks at the classroom environment in a critical constructivist mindset. Critical constructivism is a form of constructivism, which deals with the learner in a sociopolitical context, which means a way that deals with both social and political issues (Merriam Webster, n.d.). This view is very important in the discussion of bullying because it deals directly with how individuals are affected by certain situations. In this article, the effects of bullying on students inside and outside the classroom is discussed. The article stresses the relationship between the increased availability of technology to young students and the occurrences and 
severity of bullying.

Shariff and Strong-Wilson (2005), outline how cyber-bullying can affect the classroom environment for students involved in all aspects of bullying. This research article outlines that students can be affected by bullying inside the classroom, but also how it can affect them outside the classroom.

Shein (2014), talks about the importance of technology in collaboration. It helps students open up and share opinions without fear of rejection. It is also discussed in the article that it is crucial to practice responsible online collaboration. It is important that "districts set up the proper controls without extinguishing students' curiosity and excitement” (Shein, E., 2014, p.2).

Statistics Canada (2009) provides information on the cases of cyber-bullying in their article Self Reported Internet Victimization in Canada. According to Statistics Canada, cyberbullying can be defined as "hate comments spread through emails, instant messages, or postings on Internet sites” (para. 5). Statistics Canada states: "those who [use] chat sites or social networking sites were almost three times more likely than non-users to be cyber-bullied” (para. 14). These chat and social networking sites would not be available to young students if it was not for the increased availability of technology at home. It is of utmost importance that students are supervised when accessing technology in and out of the classroom, and that they are taught proper safety while using the internet.

These research articles have helped introduce me to the problem and potential solutions to cyberbullying in elementary education. I then wanted to conduct my own research study to investigate the issue of cyberbullying in more detail. 


\section{Research Context and Methods of Investigation}

I administered an online survey to peers from my $2^{\text {nd }}$ year educational technology course, as well as peers and colleagues over email and Facebook using Google Forms. These colleagues included students from Mount Royal University who are in programs other than Education and students who attend schools other than Mount Royal University. I also sent my online survey to some of my mentors who are teachers in the Calgary Board of Education (CBE).

The participants were selected on the basis of whether or not they were part of my professional learning network (PLN). I distributed my online survey to people who I knew would complete it to the best of their abilities and provide me with valuable feedback.

In total, 19 people participated in my survey. The survey I administered was completely anonymous and voluntary. The survey was only administered to participants over the age of eighteen. Because of this, I did not need to require any permission forms from parents or guardians. Participants were informed of this before completing the survey I administered.

The research was completed with the context of the elementary classroom environment in mind. As a future teacher, it is important for me to know how to implement the best possible classroom environment for my students. In my opinion, the classroom that allows for all students to feel comfortable and open to sharing their ideas is the one where the students will thrive. I believe that an environment that does not allow bullying is one where all students would feel comfortable. While conducting my research, both online, and through my data collection of surveys and interviews, I kept in mind that this information will help me as a future teacher to implement a classroom environment that is welcoming and comfortable for all students.

I created an online survey and distributed it to my peers in educational technology course. I also distributed my survey to teachers in the CBE and to some of my friends and family. I 
chose an experimental approach to gathering my information because I believe that it is the best way to collect anonymous and relevant data. The questions for the survey are outlined in Figure 2.

1) Tell me about you.

2) Have you had an experience with bullying?

3) What age group did you fit into?

4) How did bullying affect your schooling?

5) Did technology have an impact on your experience with bullying?

6) Please write a short response explaining how technology had an impact on your experience.

7) Do you think that increased availability of technology available to students at home, and at school, has an impact on the number of bullying cases in schools today?

Figure 3. Questions that were given to the participants of the survey

. Using Google Forms, I was able to create an online survey and then analyze the data in a Google Spreadsheet. This made analyzing at the data and identifying key themes very easy. The data that I collected through the online survey provided the bulk of the information that I am using in my paper. Personal experience and opinions are very important for the findings of this research manuscript. My conclusions are drawn from the background that I have found from a review of the literature, and that of personal experience and suggestions.

I interviewed two of my mentors about the effects of bullying on elementary aged school children, as well as their opinions on the increased availability of technology available to children in, and out, of the classroom. The questions that I asked during personal interviews are outlined in Figure 4. 


\section{1) How do you think the increased availability of technology has effected bullying in your classroom? \\ 2) Have you seen fewer or more cases of bullying in your classroom since the introduction of readily available technology? \\ 3) Does your school offer a Cyber-Safety course for students? \\ 4) What techniques do you use for prevention of bullying and cyber-bullying in your classroom?}

Figure 4. Personal interview questions

I used these questions to conduct personal interviews with my previous mentor teachers. These interviews provided extra depth for my paper. Having personal quotes from teachers who have had 'hands on' experience with bullying and cyber-bullying provided me with the information to fill in the blanks of my study. I asked my mentor teachers what techniques they have used to prevent bullying and cyber-bullying in the elementary classroom. Their responses to this question really helped inform my recommendations for what I can do as a future elementary teacher in the prevention of bullying.

\section{Findings}

The section outlines the findings of my research through the use of graphs and figures. Underneath each of the graphs, I have included a description of how they relate to my topic and further help me understand my conclusions. I believe that each of the figures, and the information that I received from them, outline my conclusions and give context to the basis of my study. Figure 5 demonstrates the demographic background of my research participants. 


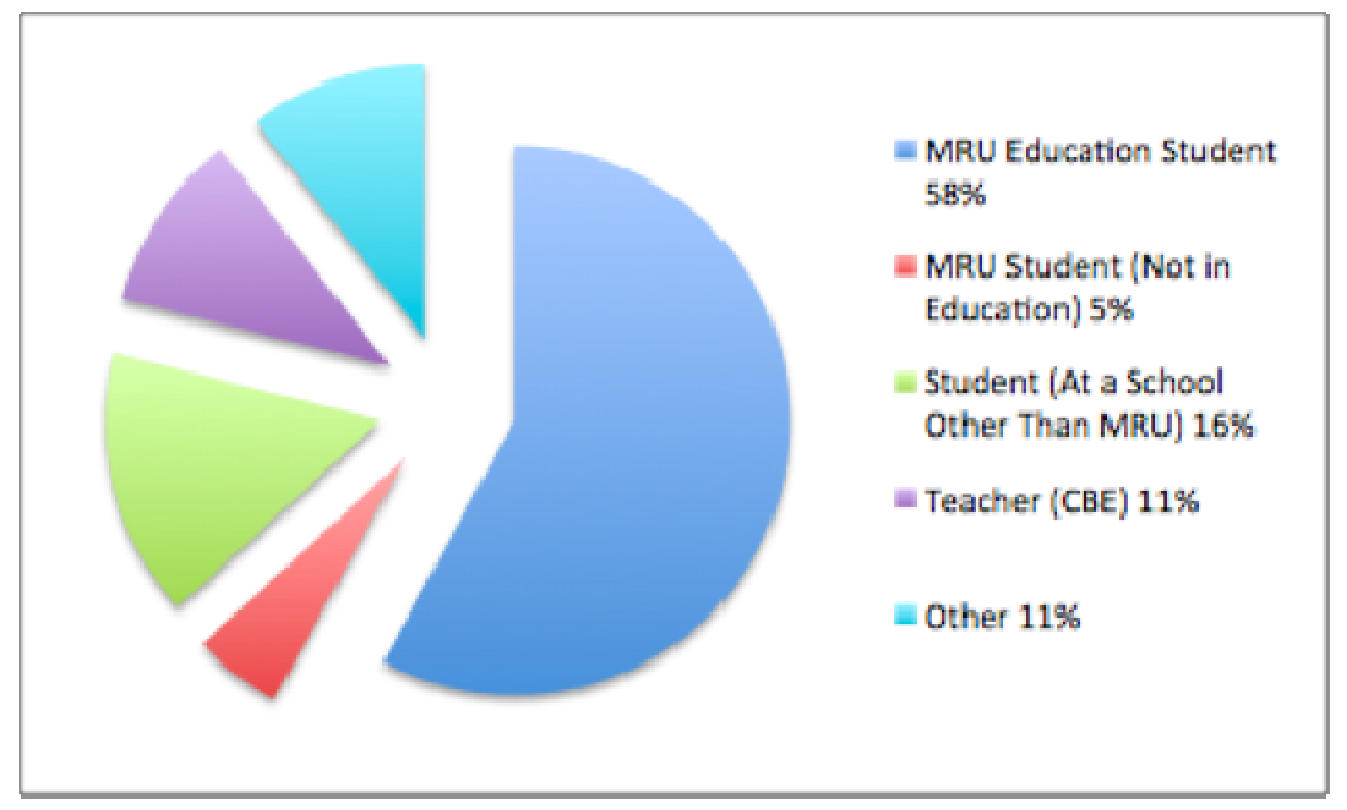

Figure 5. Demographic background of participants

Figure 5 outlines the backgrounds of the participants who completed my survey. 58\% of the participants were from Mount Royal University’s Bachelor of Elementary Education program. $5 \%$ of the participants were students at Mount Royal University who are in a program other than the Bachelor of Elementary Education program. 16\% of the participants were students at a school other than Mount Royal University. 11\% of the participants were teachers in the Calgary Board of Education. 11\% of the participants specified other - one participant is a nurse, and one participant was a Calgary Board of Education support staff.

Figure 6 illustrates the percentage of research participants who have experience with bullying. 


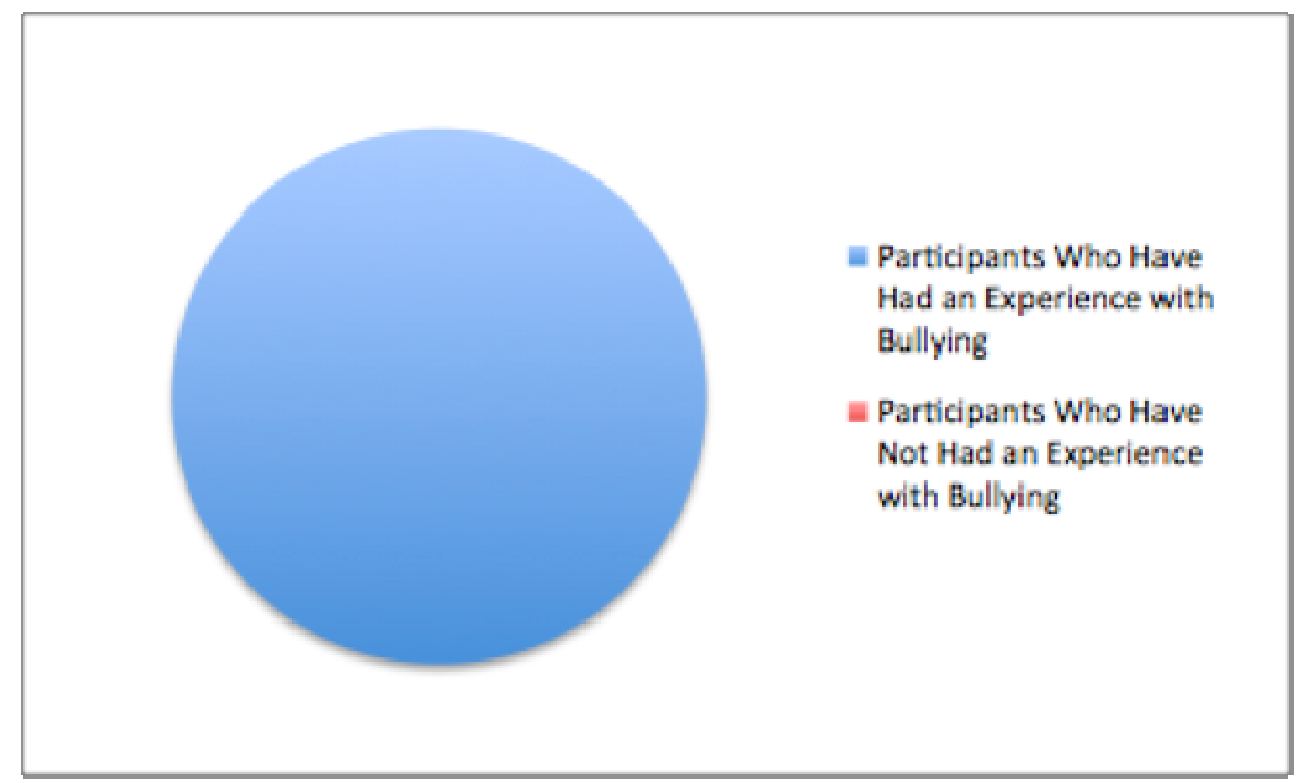

Figure 6. Participants experiences with bullying

I was amazed to discover the $100 \%$ of the participants that completed my survey reported that they had an experience with bullying. Not one person that completed my survey said that they did not have an experience with bullying in the past. In my future practice as a teacher, I need to be aware that most of the students in my classes will either be bullied, or be a bully.

The next figure highlights at what grade level the participants had experiences with bullying (Figure 7).

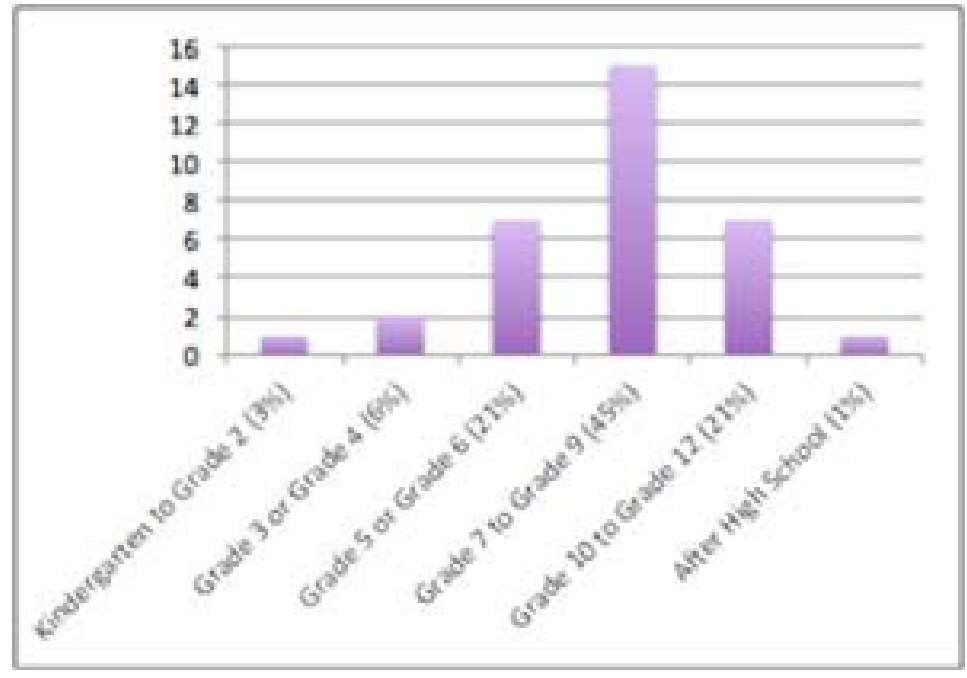

Figure 7. Age groups that participants experienced bullying 
Forty-five percent of the participants experienced bullying when they were in grades seven, eight, or nine. Twenty-one percent of the participants experienced bullying when they were in grades five or six. Twenty-one percent of the participants experienced bullying when they were in grade ten, eleven, or twelve. Six percent of the participants were in grades three or four. Three percent of the participants experienced bullying when they were in kindergarten, grade one, or two. One percent of the participants experienced bullying when they were finished high school. It is important to note that thirty percent of the participants had an experience with bullying in elementary school.

When asked how bullying affected their schooling, the following participant answers were given: dreading certain classes with certain people, never feeling good enough, feeling determined to not let the bullies win, bullying created constant tension in the classroom, constant fear, ruined concentration, "I made up reasons not to go to school”, pretending to be sick caused grades to drop significantly, feeling uncomfortable and lonely, "I had no one to count on", feeling self-conscious, and feeling distracted because they were always trying to avoid people. Three participants said that their experience with bullying made them not want to come to school.

My next survey question asked students to comment on the number of cases of bullying that involved technology (Figure 8). 


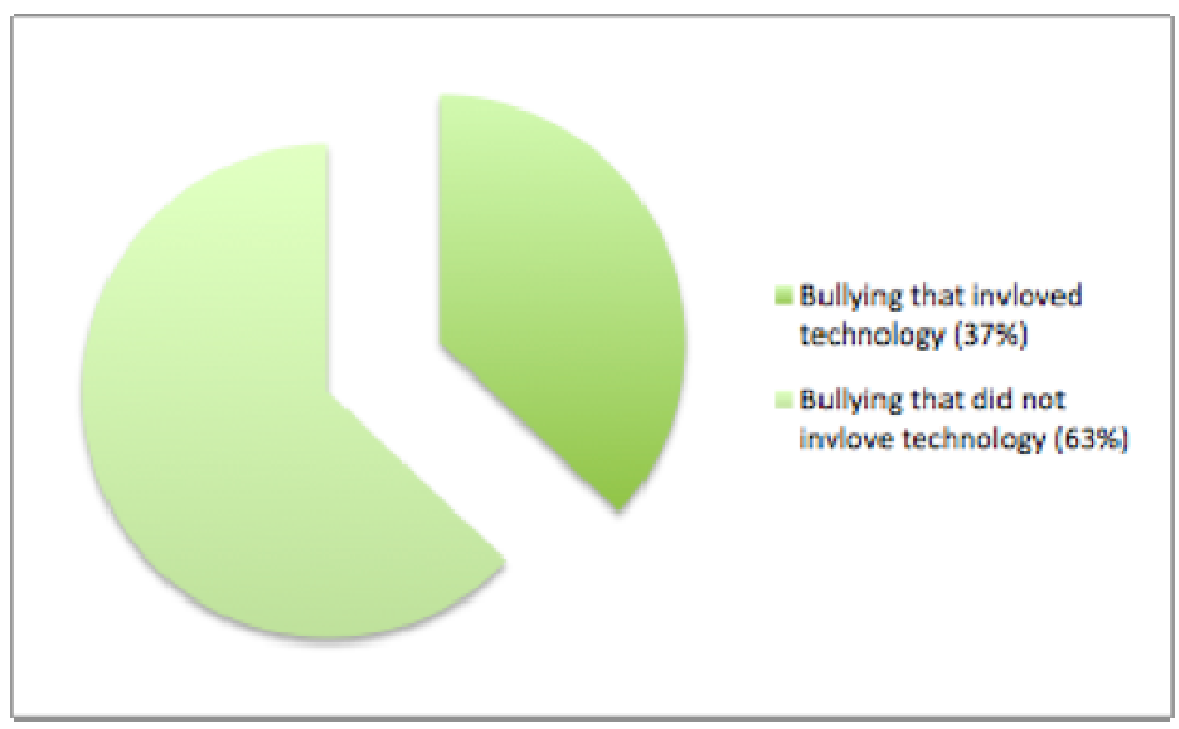

Figure 8. The number of cases of bullying that involved technology

Thirty-seven percent of the participants had an experience with bullying that involved technology. Sixty-three percent of the participants had an experience with bullying that did not involve technology.

The participants of my survey that said technology had an impact on their experience with bullying were also asked through which means this occurred. The participants who were bullied with technology made up thirty-seven percent of the participants of my survey. Some of the social media through which the bullying occurred involved the use of Facebook, Honesty Box, MSN chat, and text-messaging. In response to the question of how technology impacted their experience with bullying, one of the participants of the survey answered: "It has become very easy to bully people through the use of technology. People are often meaner when they don't have to look you in the eyes”.

The other sixty-three percent of the participants of my survey said that technology did not have an impact on their experience with bullying. Their responses consisted of technology not being a factor when they were growing up. 
Sixty-three percent of the participants said that technology was not a factor when they were growing up. For the other thirty-seven percent of the participants, technology was a factor when they were growing up, and had an impact on their experience. That change, happened in just over a decade. With this statistic, we can see that the increased availability of technology can, and does, have an effect on the number and severity of cases of bullying (Figure 9).

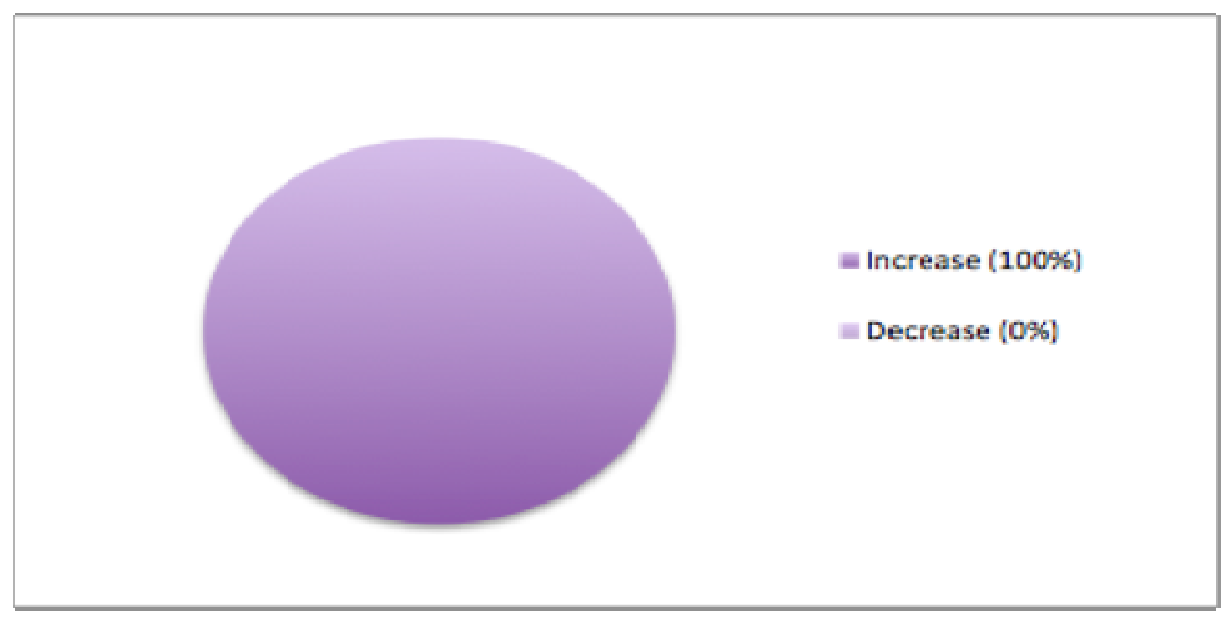

Figure 9. Does the increased availability of technology inside, and outside, of the classroom have an impact on the number of cases of bullying in schools today?

One-hundred percent of the participants believe that the increase of technology available to students inside, and outside, of the classroom increases the number of cases of bullying in schools today.

When asked if they believe the increased availability of technology to students has an impact of the number of cases and severity of bullying and cyber-bullying, one participant said: "I think that when kids have access to technology, they say things that they would not have the courage to say face to face. Text or social media allows kids to be inappropriate without being held accountable. It gives the bully protection in a way, because they are not having to deal with the consequences of their actions”. 
In a personal interview, the problems with technology and the increased availability of technology to students were discussed. Students do not realize the dangers of their actions on the Internet because it is generally anonymous. Students can get away with almost anything because of the anonymity of the action of bullying online. As more and more technology becomes available to students, we will see the number and severity of cases of bullying increase (Interview Participant 2).

\section{Conclusions and Recommendations}

One-hundred percent of the participants that took part in my online survey have had an experience with bullying. That is a staggering statistic that must be kept in mind. I think that teachers need to be aware of the probability that there will be bullying in their class. Thirty percent of the participants had experiences with bullying in elementary school.

As a future elementary school teacher, this study is relevant to me because I need to be aware of what I can do to stop bullying in its tracks. Bullying is more of an issue in a twenty-first century classroom than ever before. Knowing the warning signs of bullying, and how to educate students on Internet safety are both important for teachers to remember in stopping bullying.

According to a personal interview, the teachers can only deal with things that happen at home to an extent. Parents need to be on board with anti-bullying procedures and deal with the cases they see at home. Parents have a responsibility to teach their children how to be safe and respectful of others on the Internet (Interview Participant 1).

I believe that teachers need to be aware of the warning signs that indicate students are being bullied. Those signs include "increased aggression, increased isolation, change in appetite or sleep patterns, change in school behavior, and changes in interests or hobbies. While all children and teens periodically show such changes, when the changes are long lasting (more than 
a few days), it may indicate a problem” (Venzke, 2010, p.2).

In addition, Venzke (2010) states that, "we need to give kids the tools to be able to stand up for their own rights while respecting the rights and legitimate needs of others; to handle conflicts nonviolently; to act with integrity when confronted with difficult situations such as peer pressure to cause harm; and to develop a personal code (inner moral code) that gives them the wherewithal to do what is right in spite of external consequences and never merely because of them” (p.3). As teachers, we need to instruct our students on how to react to situations properly. We need to teach children the proper way to use technology and teach them to be safe while on the internet, including safety for others and themselves.

One survey participant indicated that "So many people have access to technology and young adults and children are not being educated on the effect that their words online have on others. It is a topic that does not seem to be discussed very often, yet almost everyone in our society has access to the technology and is at risk of bullying or being bullied” (Survey Participant, 13). The most important thing that teachers can do in the prevention of bullying and cyberbullying is to educate themselves, and the students in their class, about the dangers of the Internet and of bullying. Knowledge and awareness are the two most important factors in the prevention of bullying and cyber-bullying.

As stated in a personal interview, having a course on digital citizenship, or how to use the Internet safely, would be beneficial for students to have in order to combat bullying (Interview Participant, 1). Another interview participant also stressed the importance of having a digital citizenship course administered to students (Interview Participant 2).

Fredrick (2009) states: “[students] need to be given the resources they need to make good choices online and to have the resilience to respond to those who would tear them down” (p.45). 
The greatest thing that a teacher can do for their students is to educate them on how to be safe while using the Internet, and to be strong in times of trouble.

Further research could be done on how to administer a digital citizenship course to students. How does one teach students digital citizenship? Are there organizations that do this course? What Internet sources are useful for creating a digital citizenship course to students?

\section{References}

Fredrick, K. (2009). Mean girls (and boys): Cyberbullying and what can be done about it. (Cover Story). School Library Media Activities Monthly, 25(8), 44-45.

Merriam Webster (n.d). Retrieved March 3, 2014 from http://www.merriam-webster.com/ Pascarella, J. (2008). Confronting the challenges of critical digital literacy: An essay review critical constructivism: A primer. Educational Studies, 43(3), 246-255. doi:10.1080/00131940802117761

Oxford Dictionaries (2014). Retrieved March 21, 2014 from http://www.oxforddictionaries.com/ Shariff, S., \& Strong-Wilson, T. (2005). Chapter fourteen: Bullying and new technologies. In, Classroom Teaching, 219-240. New York, New York. Peter Lang Publishing, Inc.

Shein, E. (2014). Social media goes to school. Scholastic Administrator, 13(4), 27-29.

Statistics Canada (2009). Self reported internet victimization in canada. Retrieved January 10, 2014 from http://www.statcan.gc.ca/pub/85-002-x/2011001/article/11530-eng.htm

Venzke, B. (2010). The bully, the bullied, and the bystander: From preschool to high school How parents \& teachers can help break the cycle of violence. Parent / Community Network, 16(2). 